\title{
Myeloid Sarcoma in Remission
}

National Cancer Institute

\section{Source}

National Cancer Institute. Myeloid Sarcoma in Remission. NCI Thesaurus. Code C8613.

A myeloid sarcoma that is responding to therapy, i.e. is not progressing and possibly regressing. --2003 